\title{
The Pharmacokinetics and Interactions of Ivermectin in Humans-A Mini-review
}

\author{
Aránzazu González Canga, ${ }^{1,2}$ Ana M. Sahagún Prieto, ${ }^{1}$ M. José Diez Liébana, ${ }^{1}$ Nélida Fernández Martínez, \\ Matilde Sierra Vega, ${ }^{1}$ and Juan J. García Vieitez ${ }^{1}$
}

Received 14 September 2007; accepted 10 December 2007; published online 25 January 2008

\begin{abstract}
Ivermectin is an antiparasitic drug with a broad spectrum of activity, high efficacy as well as a wide margin of safety. Since 1987, this compound has a widespread use in veterinary medicine and it use has been extended in humans. Here we present a brief review of the information availabile regarding the pharmacokinetics and interactions of ivermectin in humans. Awareness of these characteristics could improve the clinical efficacy of Ivermectin. All Authors declare that they do not have any Conflict of interest and that the work is original. All Authors agree that the contents of the manuscript are confidential and will not be copyrighted, submitted, or published elsewhere (including the Internet), in any language, while acceptance by the Journal is under consideration.
\end{abstract}

KEY WORDS: humans; interactions; ivermectin; pharmacokinetics.

\section{INTRODUCTION}

Ivermectin is a semisynthetic derivative of avermectin $B_{1}$ and consists of an 80:20 mixture of the equipotent homologous 22,23 dehydro $\mathrm{B}_{1 \mathrm{a}}$ and $\mathrm{B}_{1 \mathrm{~b}}$. This antiparasitic agent, developed by Merck \& Co., is frequently used in veterinary medicine, due to its broad spectrum of activity, high efficacy and wide margin of safety $(1,2)$.

The first formulation destined to humans was launched in 1987, when Merck Laboratories had enough data to register ivermectin for use against onchocerciasis. The company announced that the drug would be provided at no cost to treat onchocerciasis, anywhere in the world, for as long as it was needed (3).

To control onchocerciasis, the Onchocerciasis Control Programme in West Africa was launched in 1974. The main goal of this program is to interrupt the parasite transmission cycle. Since 1987, the use of ivermectin in combination with aerial larviciding has had a remarkable impact on the transmission of the disease and greatly reduced the effect on humans. This led to the development, in 1992, of the Onchocerciasis Elimination Programme in the Americas, launched in 6 countries and, in 1995, of the African Programme for Onchocerciasis Control, both based mainly on distribution and treatment with ivermectin (4). In 1998, the Global Programme to Eliminate Lymphatic Filariasis, based on the regular mass administration of albendazole with

\footnotetext{
${ }^{1}$ Pharmacology. Department of Biomedical Sciences, Veterinary Faculty, University of Leon, Campus de Vegazana s/n 24071, Leon, Spain.

${ }^{2}$ To whom correspondence should be addressed. (e-mail: agonc@ unileon.es)
}

either ivermectin or diethylcarbamazine, was initiated, confirming the safety and efficacy of the drug combinations (5).

Presently, ivermectin is approved for use in humans in several countries (Australia, France, Japan, The Netherlands, USA, etc.), to treat onchocerciasis, lymphatic filariasis, strongiloidiasis and/or scabies.

Ivermectin is exceptionally potent, with effective dosages levels that are unusually low. In the treatment of onchocerciasis, the optimal dose of ivermectin is $150 \mu \mathrm{g} / \mathrm{kg}$, but the frequency of administration is still controversial, ranging from $150 \mu \mathrm{g} / \mathrm{kg}$ once to three times yearly. The optimal duration of treatment has not been established (6). It is effective in most patients with scabies after a single oral dose of $200 \mu \mathrm{g} / \mathrm{kg}$, but often the regimen involves two or three repeated doses, separated by interval of 1 or 2 weeks (7).

Due to the extended use of this compound in humans, the knowledge of ivermectin pharmacokinetic behavior becomes essential. Nevertheless, little is known about the kinetics and interactions of ivermectin in humans compared to animals (even if the majority of fundamental work is veterinary, there is little evidence that such knowledge has helped to inform clinicians).

Thus, in this paper, we review the literature concerning the absorption, distribution, metabolism and excretion of ivermectin in man, as well as the interactions of the compound.

\section{PHARMACOKINETICS}

The oral route is the only approved for ivermectin administration in humans. The one-compartmental model $(8,9)$, as well as the two-compartmental model (10) have been used to describe ivermectin kinetic behavior after its oral administration. In the rest of the studies cited here, 
pharmacokinetic parameters were determined using a modelindependent method.

\section{Absorption}

In healthy subjects that received $12 \mathrm{mg}$ of ivermectin as oral solution, tablets or capsules, it was shown that the solution had approximately twice the systemic availability as either of the solid forms (tablets and capsules showed similar systemic availability; Table 1). The oral solution was given as an ethanolic solution. This may affect bioavailability and could explain why the solution resulted in a twice as high availability as tablets and capsules. Nevertheless, the rate of absorption was similar in the three cases (11).

In healthy and onchocerciasis volunteers treated with $150 \mu \mathrm{g} / \mathrm{kg}$, no significant differences were found in the pharmacokinetic parameters calculated. After an initial decrease, both groups showed a tendency for a second rise in plasma levels (mostly occurring between 6 and $12 \mathrm{~h}$ after the dose) suggesting an enterohepatic recycling of the drug (12).

It was also investigated whether diminished ivermectin absorption could explain the fact that some severely infected onchocerciasis patients experience relatively few adverse effects following ivermectin treatment, although the occurrence and extent of adverse reactions have been related to infection intensity (17). According to this study, there was no observable relation between the plasma concentration after a single oral dose $(150 \mu \mathrm{g} / \mathrm{kg})$ and the occurrence of adverse reactions. Neither parasite load nor ivermectin concentrations had an influence on the occurrence of adverse reactions in the entire group of patients.

The ability to achieve adequate levels of ivermectin after oral administration in patients with disseminated strongyloidiasis may be impaired, highlighting the need for alternative routes of administration of ivermectin in these patients. Thus, ivermectin levels, in a patient with disseminated strongyloidiasis, were below the average of those reported by other authors following oral administration $\left(1.1 \mathrm{ng} \cdot \mathrm{ml}^{-1}\right.$ after ingesting a total dosage of $1,000 \mu \mathrm{g} / \mathrm{kg}$ over 3 consecutive days). This was followed by the administration of three subcutaneous doses $(200 \mu \mathrm{g} / \mathrm{kg})$, injected every 2 days, increasing ivermectin levels to $7.9 \mathrm{ng} \cdot \mathrm{ml}^{-1}$ at 1 week after the last dose, with evidence of additional metabolite accumulation and also a sustained antiparasitic effect. Thus, in these patients, who are unable to absorb oral medication, parenteral ivermectin (not licensed for use in humans) is a better option (18). In another report, a man with disseminated strongyloidiasis, severe hypoalbuminemia and paralytic ileus, received ivermectin by the oral route. Three hours after the third daily dose, the serum ivermectin concentration was only $0.8 \mathrm{ng} \cdot \mathrm{ml}^{-1}$, but it increased to $5.8 \mathrm{ng} \cdot \mathrm{ml}^{-1} 16$ hours after the first subcutaneous dose. Over the next 15 days, subcutaneous ivermectin $(200 \mu \mathrm{g} / \mathrm{kg}$, once a day) produced serum ivermectin levels between 11.4 and $17.2 \mathrm{ng} \cdot \mathrm{ml}^{-1}$ with no significant accumulation (19).

\section{Distribution}

Due to the high lipid solubility of ivermectin, this compound is widely distributed within the body.

In healthy men, the volume of distribution in the central compartment, $V_{\mathrm{c}}$, was 3.1 and $3.51 \cdot \mathrm{kg}^{-1}$, after ingesting 6 and $12 \mathrm{mg}$ of ivermectin, respectively (8). In onchocerciasis patients, with $6 \mathrm{mg}$ (tablet), the volume of distribution of the area $\left(V_{\lambda}\right)$ was $9.91 \cdot \mathrm{kg}^{-1}$ and the mean residence time (MRT) was 3.7 days (16).

The tissue distribution of ivermectin was similar in healthy and onchocerciasis volunteers treated orally. So,

Table 1. Pharmacokinetic Parameters Obtained after Ivermectin Oral Administration

\begin{tabular}{|c|c|c|c|c|c|c|}
\hline \multirow[b]{2}{*}{ Reference } & \multirow[b]{2}{*}{ Dose } & \multicolumn{3}{|c|}{ Absorption } & \multicolumn{2}{|c|}{ Elimination } \\
\hline & & $C_{\max }\left(\mathrm{ng} \cdot \mathrm{ml}^{-1}\right)$ & $t_{\max }(\mathrm{h})$ & $t_{1 / 2(\mathrm{abs})}(\mathrm{h})$ & $t_{1 / 2}(\mathrm{~h})$ & $\mathrm{Cl}\left(1 \mathrm{~kg}^{-1} \cdot \mathrm{day}^{-1}\right)$ \\
\hline \multicolumn{7}{|c|}{ Healthy subjects } \\
\hline $9^{a}$ & 12 mg (tablet) & - & - & - & 12 & - \\
\hline $8^{\mathrm{a}}$ & $6 \mathrm{mg}$ (tablet) & 23.1 & 4.3 & 0.5 & 12.6 & 4.28 \\
\hline $8^{\mathrm{a}}$ & $12 \mathrm{mg}$ (tablet) & 30.4 & 10.3 & 2.5 & 13.4 & 4.03 \\
\hline $9^{\mathrm{a}}$ & $6 \mathrm{mg}$ (tablet) & 20.2 & 4.7 & 1.4 & 11.1 & 7.57 \\
\hline $9^{\mathrm{a}}$ & $12 \mathrm{mg}$ (tablet) & 23.5 & 5.3 & 1.4 & 21.1 & 6.53 \\
\hline $9^{\mathrm{a}}$ & $18 \mathrm{mg}$ (tablet) & 31.2 & 5.1 & 1.7 & 16.7 & 10.6 \\
\hline 11 & $12 \mathrm{mg}$ (solution) & 81 & 3.6 & - & - & - \\
\hline 11 & $12 \mathrm{mg}$ (tablet) & 50 & 3.4 & - & - & - \\
\hline 11 & 12 mg (capsule) & 46 & 3.6 & - & - & - \\
\hline 12 & $150 \mu \mathrm{g} / \mathrm{kg}$ & 54.4 & 4.9 & - & 36.6 & - \\
\hline 13 & $150 \mu \mathrm{g} / \mathrm{kg}$ & 37.9 & - & - & - & - \\
\hline 14 & $150 \mu \mathrm{g} / \mathrm{kg}$ & 33.8 & - & - & & 4.70 (ㄱ) 8.40 (우) \\
\hline \multicolumn{7}{|c|}{ Onchocerciasis patients } \\
\hline 12 & $150 \mu \mathrm{g} / \mathrm{kg}$ & 52.2 & 5.2 & - & 35.0 & - \\
\hline 15 & $150 \mu \mathrm{g} / \mathrm{kg}$ & 39 & 5.6 & - & 16 & - \\
\hline 16 & $6 \mathrm{mg}$ (tablet) & 38.2 & 4.7 & - & 54.5 & 3.1 \\
\hline 17 & $150 \mu \mathrm{g} / \mathrm{kg}$ & & & & 19.9 & - \\
\hline
\end{tabular}

- Unknown data; $C_{\max }$ maximum plasma concentration; $t_{\max }$ time to reach $C_{\max } ; t_{1 / 2 a b s}$ absorption half-life; $t_{1 / 2}$ elimination half-life; $C l$ total body clearance

${ }^{a}$ One-compartment model 
infection with Onchocerca volvulus does not appear to affect the distribution of this drug. The compound was present in fat, skin, subcutaneous fascia and nodules and in worm fragments. Fat showed the highest and most persistent levels, whilst values for skin, nodular tissues, and worms were comparable, being the lowest concentrations found in the subcutaneous fascia (12). In patients with Onchocerca volvulus infection treated orally with ivermectin $(150 \mu \mathrm{g} / \mathrm{kg})$, Elkassaby (15) also detected the drug in the nodular tissue of the parasite and in worm fragments. After subcutaneous administration $(500 \mu \mathrm{g} / \mathrm{kg})$ to cattle with nodules of Onchocerca ochengi (a cattle parasite that can be used as a model of $O$. volvulus), high concentrations were detected in the capsule wall and inside the nodule (55 and $45 \mathrm{ng} \cdot \mathrm{g}^{-1}$ on day $2 ; 60$ and $30 \mathrm{ng} \cdot \mathrm{g}^{-1}$ on day 7$)$. So, the poor penetration of ivermectin into the nodules could not explain the lack of efficacy against adult filariae (20).

In the skin, the peak concentration of the drug in squames, sebum and sweat on the forehead and the antithenar was $8 \mathrm{~h}$ after a $12 \mathrm{mg}$ oral dose and decline quickly beyond $24 \mathrm{~h}(21)$.

Ivermectin binds strongly to plasma proteins in healthy subjects $(93.2 \%)$ (22). It was also high in onchocerciasis patients $(93.1 \%)$, with a specific binding for serum albumin. There were two binding sites, with an association constant of $2 \times 10^{8} \mathrm{~mol}^{-1}$ at the primary site. Such avid binding assumes great importance as the drug is administered in world areas where malnutrition and hypoalbuminemia are common, so in these patients a decrease in plasma proteins and, consequently, a higher free fraction of ivermectin could be expected. Nevertheless, acetylsalicylic acid does not interfere with ivermectin binding (16).

Ivermectin was not detected in the cerebrospinal fluid of a man with disseminated strongyloidiasis, severe hypoalbuminemia and paralytic ileus, after five subcutaneous doses of ivermectin, when the serum level was $12.1 \mathrm{ng} \cdot \mathrm{ml}^{-1}$ (18).

\section{Elimination}

Studies regarding the metabolism of ivermectin in humans are scarce. This drug is extensively metabolized by human liver microsomes by cytochrome P450. The predominant isoform responsible for the biotransformation of this compound in the liver of humans is cytochrome P-4503A4, converting the drug to at least 10 metabolites, most of them hydroxylated and demethylated derivatives (23). In plasma, radioactive metabolites were reported after the oral administration of ivermectin to healthy volunteers (10).

Data concerning excretion can be observed on Table 1. No differences in the elimination half-life were detected among healthy and onchocerciasis subjects (12). It was also suggested that the kinetics of ivermectin (its elimination halflife is around a day) were somewhat disconnected from its pharmacodynamics (antiparasitic events persisting for several months after a single dose of the drug) (11).

A significant effect of gender was found in ivermectin pharmacokinetics in healthy volunteers orally treated with $150 \mu \mathrm{g} / \mathrm{kg}$, with a lower total body $\mathrm{Cl} / \mathrm{F}$ in males compared to females (see Table 1) (14).

In connection with the excretion pathways, ivermectin and its metabolites were excreted mainly in faeces and only
$1 \%$ in urine. Positive identification was obtained for the presence of 3 "-O-desmethyl- $\mathrm{H}_{2} \mathrm{~B}_{1 \mathrm{a}}$, and 22,23-dihydroavermectin $\mathrm{B}_{1 \mathrm{a}}$ monosacharide in urine and faeces, respectively ${ }^{10}$. Other authors who tried to determine ivermectin in urine (8, $9,16)$ did not find the parent drug nor its metabolites.

Finally, in the milk of healthy women administered $150 \mu \mathrm{g} / \mathrm{kg}$, the maximum concentration $\left(14.1 \mathrm{ng} \cdot \mathrm{ml}^{-1}\right.$ ) was reached in $6.5 \mathrm{~h}$ (13). On the basis of this information, a breast-fed child would receive an average dose of only $2.75 \mu \mathrm{g} / \mathrm{kg}$ via milk. Thus, these authors did not recommend excluding breastfeeding mothers from mass ivermectin therapies, as they only represent $5-10 \%$ of the population in the areas hyperendemic with onchocerciasis.

\section{INTERACTIONS}

Several authors evaluated the effect of ivermectin coadministration with different drugs employed to control helminthes. To interrupt the transmission of onchocerciasis in humans, the combination of ivermectin and doxycycline is highly effective as, in infested patients, the ingestion of the anthelmintic (200 $\mu \mathrm{g} / \mathrm{kg}$, single dose) and the antibacterial $(100 \mathrm{mg} / \mathrm{kg}$, daily for 6 weeks), kept the microfiladermia levels low more time than did ivermectin alone. Doxycycline enhanced ivermectin-induced suppression of microfiladermia, as it sterilize adult female worms for a few months by depletion of symbiotic endobacteria of filariae, Wolbachia spp. (24) (essential for their survival and reproduction). Other studies showed that, to control onchocerciasis, the combination of ivermectin with other drugs offers no advantage over ivermectin alone. Thus, in infected patients, the ingestion of ivermectin had no effect on the kinetics of an oral dose of albendazole and there was no additive effect of both drugs against the parasite compared to ivermectin given alone $(25,26,27)$. Albendazole $(400 \mathrm{mg})$ did not modify the kinetic behavior of a single oral ivermectin dose (12 mg) (27). Also in onchocerciasis patients, the antiparasitary efficacy was similar when administering a single ivermectin dose $(150 \mu \mathrm{g} / \mathrm{kg}$, on day 1$)$ followed by amorcazine $(3 \mathrm{mg} / \mathrm{kg}$ twice daily, on days 8,9 and 10) than when administering ivermectin alone (28). Similarly, the combination of ivermectin $(200 \mu \mathrm{g} / \mathrm{kg})$ and levamisole $(2.5 \mathrm{mg} / \mathrm{kg})$ was neither macrofilaricidal nor more effective against the microfilariae and the adult worms than ivermectin alone, although levamisole increased ivermectin plasma bioavailability in these patients (29).

The efficacy of drugs available for the treatment of infection with Trichuris trichiura is low in humans. Nevertheless, single-dose treatment with albendazole (400 mg)ivermectin $(200 \mu \mathrm{g} / \mathrm{kg})$ appears to be highly effective against trichuriasis, being higher than when administering albendazole alone or with diethylcarbamazine $(6 \mathrm{mg} / \mathrm{kg})(30)$.

Thus, ivermectin interactions with another concurrently administered drugs can occur. This issue becames important, as combination chemotherapy is being used with increasing frequency as resistance to antiparasitic agents is becoming more widespread.

Regarding bleeding disorders, haematomatous swellings were reported in 2 out of 28 onchocerciasis patients treated with ivermectin $(150 \mu \mathrm{g} / \mathrm{kg})$, and prothrombin times were significantly above baseline by one week to one month after 
drug ingestion, suggesting an antagonist effect against vitamin K (31). Nevertheless, in other 20 subjects, no changes were observed in prothrombin nor in thromboplastin times compared with baseline results, during 13 days after the ingestion of 220$420 \mu \mathrm{g} / \mathrm{kg}$ of ivermectin (32); bleeding disorders were not found in 15,000 patients treated with ivermectin $(150 \mu \mathrm{g} / \mathrm{kg})(33)$. Moreover, prolonged prothrombin ratios were observed in 148 subjects given ivermectin orally. Although no patients suffered bleeding complications, factor II and VII levels were reduced in most of them, suggesting interference with vitamin $\mathrm{K}$ metabolism. Ivermectin has a minimal effect on coagulation and concern about mass treatment for this reason appears to be unjustified (34). Finally, a man that had been on long-term oral anticoagulant therapy with acenocoumarol showed a persistent, excessive hypocoagulability while using insecticides (ivermectin and metidation) without protection to treat trees. So, it is to be taken into account that these types of interactions can exist and could cause hemorrhagic complications (35).

Information about the influence of foods in the pharmacokinetics of ivermectin is scarce. The knowledge of the influence of alcohol in ivermectin kinetic behaviour is scarce; co-ingestion of alcoholic drinks however is not recommended, because of ivermectin association with GABA receptors and the effect of alcohol in the central nervous system. In healthy volunteers administered ivermectin orally $(150 \mu \mathrm{g} / \mathrm{kg})$, plasma levels were significantly higher when coadministered with $750 \mathrm{ml}$ of beer than with $750 \mathrm{ml}$ of water; the plasma concentrations were significantly higher in patients who drank beer $(66.3,109$, and $97.2 \mathrm{ng} / \mathrm{ml}$ at 1,3 and $4 \mathrm{~h}$, respectively) vs. those who drank water $(44.0,67.5$, and $58.7 \mathrm{ng} / \mathrm{ml}$, respectively, $P<0.01$ at each time point) (36).

Finally, ivermectin $(150 \mu \mathrm{g} / \mathrm{kg})$ was administered to 16 individuals with water or orange juice $(750 \mathrm{ml})$. Orange juice decreased AUC $\left(15.7 \mathrm{ng} \cdot \mathrm{d} \cdot \mathrm{ml}^{-1}\right)$ and $C_{\max }\left(20.7 \mathrm{ng} \cdot \mathrm{ml}^{-1}\right)$ (water: $33.8 \mathrm{ng} \cdot \mathrm{ml}^{-1} ; 24.3 \mathrm{ng} \cdot \mathrm{d} \cdot \mathrm{ml}^{-1}$ ), possibly because fruit juices and constituents are potent inhibitors of certain drug transporters (14).

\section{CONCLUSION}

Although the efficacy of ivermectin has been established in humans against several parasite diseases, the pharmacokinetic properties of this compound are less well known in humans compared to animals. Potential drug-drug interactions and drug-food interactions exist for ivermectin, which should be considered during therapeutic use of this drug.

\section{REFERENCES}

1. M. H. Fisher, H. Mrozik. Chemistry. In W. C. Campbell (ed.), Ivermectin and abamectin: Springer, New York, 1989 pp. 1-23.

2. J.W. Steel. Pharmacokinetics and metabolism of avermectins in livestock. Vet. Parasitol 48:45-77 (1993).

3. D. Lindley. Merck's new drug free to WHO for river blindness programme. Nature 329:752 (1987).

4. M. Winne, A. P. Plaisier, E. S. Alley et al. Can ivermectin mass treatments eliminate onchocerciasis in Africa? Bull. WHO 80:384-390 (2002).

5. D. H. Molyneux, and N. Zagaria. Lymphatic filariasis elimination: progress in global programme development. Ann. Trop. Med. Parasitol 96:15-40 (2002).
6. C. D. Enk. Onchocerciasis: river blindness. Clin. Dermatol 24:176-180 (2006).

7. A. L. Dourmishev, L. A. Dourmishev, and R. A. Schwartz. Ivermectin: pharmacology and application in dermatology. Int. $J$. Dermatol 44:981-988 (2005).

8. D. R. Krishna, and U. Klotz. Determination of ivermectin in human plasma by high-performance liquid chromatography. Arzneimittelforschung 43:609-611 (1993).

9. Q. C. Long, B. Ren, S. X. Li, and G. X. Zeng. Human pharmacokinetics of orally taken ivermectin. Chin. J. Clin. Pharmacol 17:203-206 (2001).

10. D. W. Fink, and A. G. Porras. Pharmacokinetics of ivermectin in animals and humans. In W. C. Campbell (ed.), Ivermectin and abamectin: Springer, New York, 1989, pp. 113-130.

11. G. Edwards, A. Dingsdale, N. Helsby, M. L. Orme, and A. Breckenridge. The relative systemic availability of ivermectin after administration as capsule, tablet, and oral solution. Eur. J. Clin. Pharmacol 35:681-684 (1988).

12. O. Z. Baraka, B. M. Mahmoud, C. K. Marschke, T. G. Geary, A. Homeida, and J. F. Williams. Ivermectin distribution in the plasma and tissues of patients infected with Onchocerca volvulus. Eur. J. Clin. Pharmacol 50:407-410 (1996).

13. J. E. Ogbuokiri, B. C. Ozumba, O. P. Okonkwo. Ivermectin levels in human breast milkEur. J. Clin. Pharmacol 46:389-390 (1993).

14. S. R. Vanapalli, Y. Chen, V. L. Ellingrod, et al. Orange juice decreases the oral bioavailability of ivermectin in healthy volunteers. 2003 Annual Meeting of the American Society for Clinical Pharmacology and Therapeutics. Washington (USA), 25 April, 2003.

15. M. H. Elkassaby. Ivermectin uptake and distribution in the plasma and tissue of sudanese and mexican patients infected with Onchocerca volvulus. Trop. Med. Parasitol 42:79-81 (1991).

16. P. O. Okonkwo, J. E. Ogbuokiri, E. Ofogebu, and U. Klotz. Protein binding and ivermectin estimations in patients with onchocerciasis. Clin. Pharmacol. The 53:426-430 (1993).

17. F. L. Njoo, W. M. J. Beek, H. J. Keukens, H. Wilgenburg, J. Oosting, and J. S. Stilma. Ivermectin detection in serum of onchocerciasis patients: relationship to adverse reactions. Am. J. Trop. Med. Hyg 52:94-97 (1995).

18. F. M. Marty, C. M. Lowry, M. Rodriguez et al. Treatment of human disseminated strongyloidiasis with a parenteral veterinary formulation of ivermectin. CID 41:e5-8 (2005).

19. S. A. Turner, J. D. MacLean, L. Fleckenstein, and C. Greenaway. Parenteral administration of ivermectin in a patient with disseminated strongyloidiasis. Am. J. Trop. Med. Hyg 73:911914 (2005).

20. H. F. Cross, B. M. Bronsvoort, G. Wahl, A. Renz, D. Achu-Kwi, and A. J. Trees. The entry of ivermectin and suramin into Onchocerca ochengi nodules. Ann. Trop. Med. Parasitol 91:393401 (1997).

21. N. Haas, U. Lindemann, K. Frank et al. Rapid and preferential sebum secretion of ivermectin: a new factor that may determine drug responsiveness in patients with scabies. Arch. Dermatol 138:1618-1619 (2002).

22. U. Klotz, J. E. Ogbuokiri, and P. O. Okonkwo. Ivermectin binds avidly to plasma proteins. Eur. J. Clin. Pharmacol 39:607-608 (1990).

23. Z. Zeng, N. W. Andrew, B. H. Arison, D. Luffer-Atlas, and R. W. Wang. Identification of cytochrome P4503A4 as the major enzyme responsible for the metabolism of ivermectin by human liver microsomes. Xenobiotica 28:313-321 (1998).

24. A. Hoerauf, S. Mand, O. Adjei, B. Fleischer, and D. Büttner. Depletion of Wolbachia endobacteria in Onchocerca volvulus by doxycycline and microfilaridermia after ivermectin treatment. Lancet 537:1415-1416 (2001).

25. K. Awadzi, M. Hero, N. O. Opoku et al. The chemotherapy of onchocerciasis: clinical evaluation of albendazole in patients with onchocerciasis; effects of food and pretreatment with ivermectin on drug response and pharmacokinetics. Ann. Trop. Med. Parasitol 45:203-208 (1994).

26. K. Awadzi, E. T. Addy, N. O. Opoku, A. Plenge-Böning, and D. W. Büttner. The chemotherapy of onchocerciasis: ivermectin in combination with albendazole. Trop. Med. Parasitol 46:213-220 (1995)

27. K. Awadzi, G. Edwards, B. O. Duke et al. The coadministration of ivermectin and albendazole: safety, pharmacokinetics and 
efficacy against Onchocerca volvulus. Ann. Trop. Med. Parasitol 97:165-178 (2003).

28. K. Awadzi, N. O. Opoku, S. K. Attah et al. The safety and efficacy of amorcazine in African onchocerciasis and the influence of ivermectin on the clinical and parasitological response to treatment. Ann. Trop. Med. Parasitol 91:281-296 (1997).

29. K. Awadzi, G. Edwards, Opoku et al. The safety, tolerability and pharmacokinetics of levamisole alone, levamisole plus ivermectin, and levamisole plus albendazole, and their efficacy against Onchocerca volvulus. Ann. Trop. Med. Parasitol 98:595-614 (2004).

30. M. M. Ismail, and R. L. Jayakody. Efficacy of albendazole and its combinations with ivermectin or diethylcarbamazine (DEC) in the treatment of Trichuris trichiura infections in Sri Lanka. Ann. Trop. Med. Parasitol 93:501-504 (1999).
31. M. M. Homeida, I. S. Bagi, H. W. Ghalib et al. Prolongation of prothrombin time with ivermectin. Lancet 1:1346-1347 (1988).

32. F. O. Richards, M. B. McNeely, R. T. Bryan et al. Ivermectin and prothrombin time. Lancet 1:1139 (1989).

33. M. C. Pacqué, B. Muñoz, A. T. White, P. N. Williams, and B. M. Greene. Ivermectin and prothrombin time. Lancet 1:1140 (1989).

34. J. A. Whitworth, C. R. Hay, A. M. McNicholas, D. Morgan, G. H. Maude, and D. W. Taylor. Coagulation abnormalities and ivermectin. Ann. Trop. Med. Parasitol 86:301-305 (1992).

35. M. A. Fernández, S. Ballesteros, and J. Aznar. Oral anticoagulants and insecticides. Thromb. Haemost 80:724 (1998).

36. E. N. Shu, E. O. Onwujekwe, and P. O. Okonkwo. Do alcoholic beverages enhance availability of ivermectin? Eur. J. Clin. Pharmacol 56:437-438 (2000). 